\title{
A STUDY OF MUSCULOSKELETAL DISORDERS AMONG VISUAL DISPLAY TERMINAL WORKERS
}

\author{
SAMSUDDIN N.A. ${ }^{1, a}$ and DARUIS, D.D.I. ${ }^{2, b}$
}

\author{
${ }^{1}$ Faculty of Engineering and Built Environment, Universiti Kebangsaan Malaysia, 43600 UKM, \\ Bangi, Selangor, MALAYSIA \\ ${ }^{2}$ Dept. of Mechanical Engineering, Faculty of Engineering, Universiti Pertahanan Nasional \\ Malaysia, Kem Sg. Besi, 57000 Kuala Lumpur, MALAYSIA
}

a hayatiarni@gmail.com, ${ }^{b}$ dian@upnm.edu.my

Keywords: Musculoskeletal disorders (MSD), visual display terminal (VDT), ergonomics

\begin{abstract}
This study investigated the effectiveness of workstation ergonomic intervention in reducing musculoskeletal disorders (MSD) in Visual Display Terminal (VDT) workers. The study was carried out at one of a Multinational Company in Petaling Jaya, Selangor. Sixty Heavy VDT workers were selected randomly as case study respondents. Questionnaires were given to 60 respondents to investigate their awareness in ergonomic intervention, job-related factors that contributing to musculoskeletal disorders, as well as MSD severity and symptoms among them. Then, 30 workers who are heavy VDT users were selected to receive the education and ergonomics interventions, whereas another 30 receive the education and ergonomic intervention, whereas another 30 workers were assigned as a control group. The two groups were then crossed-over after sixth week, and follow-up questionnaire s we given to all of them once again. The results for both questionnaires, before and after the ergonomics intervention, were then analyzed for this case study. The interventions include ergonomics leaflets, ergonomic posters, online ergonomic education and ergonomic working posture guidance. The outcomes suggested that a participation in an ergonomics program, even though in a short duration and minimally disruptive to the normal workplace routine, can still contribute to a rapid effect on improving work posture. Although improper posture is associated to be the main risk factor for work-related musculoskeletal disorders, multigroup and long-term randomized trial are required to establish the effectiveness or workstation ergonomic intervention in reducing musculoskeletal disorders in VDT workers. In conclusion, there is significant evidence that individualized ergonomic interventions may contribute to improve workrelated posture and reduce MSD injuries for VDT workers.
\end{abstract}

\section{Introduction}

This research purpose is to study musculoskeletal disorders (MSD) symptom among visual display terminal (VDT) workers, as MSD injuries are commonly reported among VDT workers. One of the main topic in improving work-related posture and general health of VDT workers is workstation ergonomic intervention. Therefore, this study will review ergonomic intervention implementation, effectiveness and benefits by conducting case study on the selected VDT workers.

The common characteristics that contribute to the onset of MSD are repetitive movements, sustained postures, and incorrect work postures. Sitting in incorrect, fixed positions for a long time increases the biomechanical stress on the back, neck, shoulders, and upper limbs. Incorrect sitting posture could play an important role in determining both an increase of stress within the disc and a sustained stretch of passive lumbar structure in combination with poor back muscle activity. Moreover, the activity to sustain non-neutral postures during computer use, such as neck rotation and shoulder abduction. Are defined as risk factors leading to the onset of symptoms in the neck and shoulder area. Even though an elevated risk of low back pain (LBP) associated with prolonged sitting does not necessarily indicate to a higher prevalence in VDT workers in comparison to the other occupational groups, the hypothesis that prolonged sitting is contributing to a higher risk of LBP in comparison to workplace conditions that allow more postural variation cannot be excluded [1]. 
The study was carried out in one of the biggest Multi National Company in Malaysia, which is located in Petaling Jaya, Selangor. The department chosen were the finance department, which is the company's Finance Center for Asia Pasific region. All respondents selected were the one who predominantly in a sitting position, using desktop computer and telephones throughout the workday. Their working hours were from 9 a.m. to 6 p.m., and working at the office only, throughout the study period. The 60 respondents involved were VDT users at workspace as shown in Figure 1, with prolonged sitting jobs in front of the computer for at least more than 4 hours daily, and the total for more than 20 hours weekly.

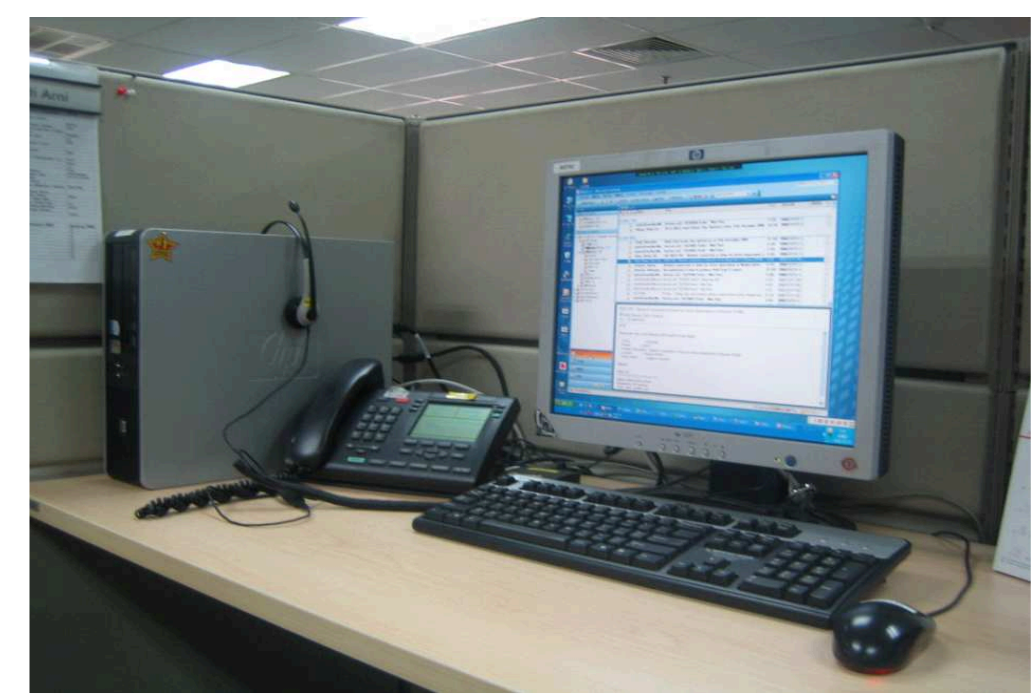

Figure 1 Video display terminal with desktop monitor, keyboard and mouse

Chairs and table are very common for workplaces that used Video Display Terminal (VDT) for their daily tasks. Various problems have been associated with the use of VDTs, including visual problem, muscle aches and pains, repetitive trauma injuries such as carpal tunnel syndrome and job stress. Therefore, when workstations are poorly designed, the result is poor posture due to strains are placed on a particular group of muscles, which will increase discomfort level [2].

The presence of MSD risk factors may be determined through the analysis of human body motion while performing a task, such as typing at a VDT workstation. By analyzing human body motion while performing a task, the degree of exposure to these risk factor may be quantified [3]. Numerous studies of VDT workstations indicated the impact of workstation's chair parameters and VDT equipment positioning on back pain and neck pain, respectively. Studies have evaluated the influence of various chair parameters on the development of back pain, including seat type, seat height, backrest type, backrest angle, lumbar support, and presence of armrests. These studies prominently identified the effects of these parameters and adjustability features on physiological response (for example, muscle activity) ad subjective discomfort ratings and user perceptions [4].

Even though the usage of computer provided opportunities for increasing productivity, there are some negative impact to extensive computer use. The amount of time one spends working on a computer is associated with the possibility of experiencing symptoms of MSD. When VDT works were observed together with worker from different seated posture activities (i.e. light assembly work, office work, listening / lecture attendance and cashier work), it was clear that the VDT workers moved the least and were most prone to musculoskeletal problems [5].

\section{Methodology}

The research aims study about musculoskeletal disorders among VDT users. Sixty heavy VDT workers were selected randomly as case study respondents. Questionnaires were given to 60 respondents to investigate their awareness in ergonomic intervention, job-related factors that 
contributing to musculoskeletal disorders, as well as MSD severity and symptoms among them. Then, 30 VDT workers were selected to receive the education and ergonomic intervention, whereas another 30 workers were assigned as a control group. The two group were then crossed-over after the sixth week, and follow-up questionnaire were given to all of them once again. The result for both questionnaires, before and after the ergonomics intervention, was then analyzed for this case study. The interventions include ergonomic leaflets, ergonomic posters, online ergonomic education and ergonomic working posture guidance. Figure 2 illustrates the case study structure.

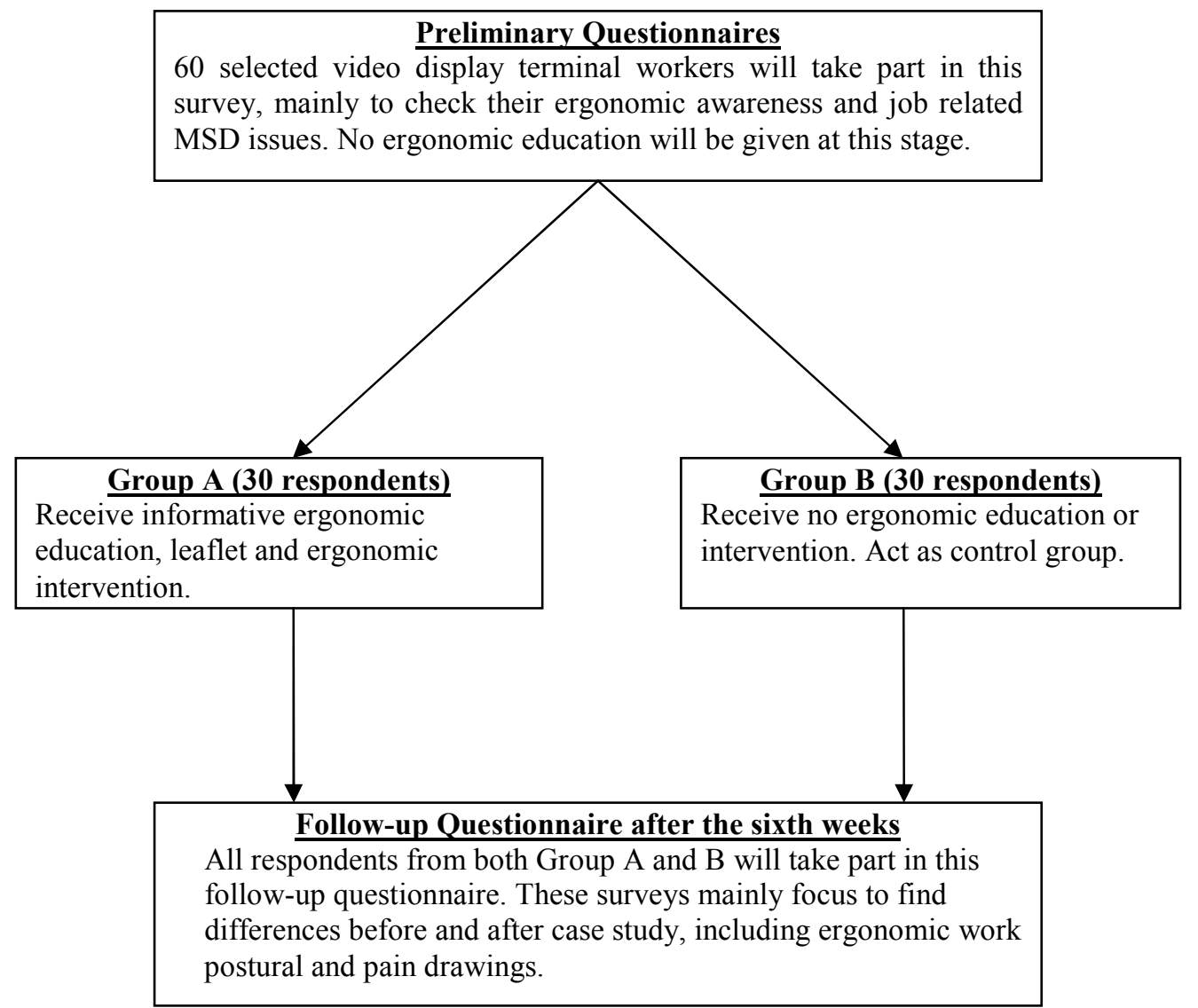

Figure 2 Case Study structure

\section{Results and Discussion}

The goals of this case study were to teach VDT users to evaluate and adjust their own workstation (Self-directed intervention), and educate the VDT workers on their responsibility of maintaining an ergonomic workstation, with the primary objective. Thus, the analysis used each respondent as his or her own control. Changes in workstation configuration, posture and symptoms were calculated and then summed across respondents to determine the proportion of subjects' responses for each outcome variable of interest.

Respondent's demography about age, sex, working duration and working experience are collected as in Table 1. 
Table 1 Demographic characteristics of respondents $(\mathrm{N}=60)$

\begin{tabular}{|c|c|c|c|}
\hline Demographic characteristics & Range & Frequency $(\mathrm{N})$ & Percent $(\%)$ \\
\hline \multirow[t]{2}{*}{ Gender } & Male & 20 & 33.33 \\
\hline & Female & 40 & 66.67 \\
\hline \multirow[t]{6}{*}{ Age } & $<20$ & 0 & 0.00 \\
\hline & $20-29$ & 10 & 16.67 \\
\hline & $30-39$ & 38 & 63.33 \\
\hline & $40-49$ & 9 & 15.00 \\
\hline & $50-59$ & 3 & 5.00 \\
\hline & $\geq 60$ & 0 & 0.00 \\
\hline \multirow[t]{6}{*}{ Years of working } & $<1$ & 2 & 3.33 \\
\hline & $1-5$ & 16 & 26.67 \\
\hline & $6-10$ & 23 & 38.33 \\
\hline & $11-15$ & 12 & 20.00 \\
\hline & $16-20$ & 4 & 6.67 \\
\hline & $>20$ & 3 & 5.00 \\
\hline \multirow{5}{*}{$\begin{array}{l}\text { Hours spent at the keyboard } \\
\text { daily }\end{array}$} & $<1$ & 0 & 0.00 \\
\hline & $2-4$ & 0 & 0.00 \\
\hline & $5-6$ & 24 & 40.00 \\
\hline & $7-8$ & 31 & 51.67 \\
\hline & $>8$ & 5 & 8.33 \\
\hline
\end{tabular}

Higher percentage of VDT workers are from age 30 to 39 years old (63.3\%). Female respondents are higher than male. Most of respondents work more than 6 hours a days $(60 \%)$ and have more than 6 years experience $(70 \%)$.

The cause percentage of work-related job factor and conditions that contributed to the development of MSD was then calculated, and presented in Table 2. Changes in workstation configuration is shown in Table 3. Eighty nine percent agreed that continuing to work in injured or hurt was the top reason contributing to MSD. Apart from that, $87 \%$ agreed with insufficient breaks or pauses during workday, $85 \%$ agreed with working in the same positions for long period, and $81 \%$ agreed that working in awkward or cramped positions, were the main reasons contributing to MSD.

Changes in discomfort symptom severity is shown in Table 4 . The symptoms asked were mainly for head/ eyes, neck/ upper back, low back, shoulder, elbow/ forearm and hand/wrist areas. For group A, significant reductions can be seen in four out of the six body regions which were shoulder, hand/wrist, low back and neck/upper back. The elbow/forearm was only borderline significant, while no significant changes for back. The elbow/forearm was only borderline significant, while no significant changes for the remaining had/eyes. Overall, approximately $20-50 \%$ of workers reported improving severity for each of the symptoms. 
Table 2 Results for Job Factors that Contributed to MSD

\begin{tabular}{ll}
\hline Job Factors & Cause Percentage \\
\hline Performing the same task over and over & $56 \%$ \\
Working very fast for short period & $37 \%$ \\
Having to handle or grasp small object & $22 \%$ \\
Insufficient breaks or pauses during workday & $87 \%$ \\
Working in a awkward or cramped position & $81 \%$ \\
Working in the same position for long periods & $85 \%$ \\
Bending or twisting your back in an awkward way & $72 \%$ \\
Working near or at your physical limits & $79 \%$ \\
Reaching or working over your head or away from your body & $63 \%$ \\
Continuing to work when injured or hurt & $89 \%$ \\
\hline
\end{tabular}

Table 3 Changes in workstation setup after the ergonomic intervention

\begin{tabular}{ccccccc}
\hline \multirow{2}{*}{ Variable } & Before $(\mathrm{N})$ & \multicolumn{2}{c}{ Group A (N=30) } & \multirow{2}{*}{ Group B (N=30) } \\
\cline { 3 - 4 } & & After $(\mathrm{N})$ & Changes & & After $(\mathrm{N})$ & Changes \\
\hline $\begin{array}{c}\text { Head } \\
\text { position }\end{array}$ & $40.0 \%(12)$ & $83.3 \%(25)$ & $\begin{array}{c}\text { Improved } \\
43.3 \%\end{array}$ & $33.3 \%(10)$ & $36.7 \%(11)$ & $\begin{array}{c}\text { Improved } \\
\text { Keyboard } \\
\text { position }\end{array}$ \\
$\begin{array}{c}\text { Mouse } \\
\text { position }\end{array}$ & $46.7 \%(11)$ & $50.0 \%(15)$ & $\begin{array}{c}\text { Improved } \\
13.3 \%\end{array}$ & $36.7 \%(11)$ & $36.7 \%(11)$ & No changes \\
& $46.7 \%(14)$ & $93.3 \%(28)$ & $\begin{array}{c}\text { Improved } \\
46.6 \%\end{array}$ & $40.0 \%(12)$ & $46.7 \%(14)$ & $\begin{array}{c}\text { Improved } \\
6.7 \%\end{array}$ \\
\hline
\end{tabular}

Table 4 results for the changes in the 6 types of pain and discomfort symptom severity

\begin{tabular}{|c|c|c|c|c|c|c|}
\hline \multirow[b]{2}{*}{ Body part } & \multirow{2}{*}{$\begin{array}{l}\text { Improved } \\
(\mathrm{N})\end{array}$} & \multicolumn{2}{|c|}{ Group A $(\mathrm{N}=30)$} & \multirow{2}{*}{$\begin{array}{l}\text { Improved } \\
(\mathrm{N})\end{array}$} & \multicolumn{2}{|c|}{ Group B $(\mathrm{N}=30)$} \\
\hline & & $\begin{array}{l}\text { No change } \\
\text { (N) }\end{array}$ & $\begin{array}{l}\text { Worsened } \\
(\mathrm{N})\end{array}$ & & $\begin{array}{l}\text { No change } \\
\text { (N) }\end{array}$ & $\begin{array}{l}\text { Worsened } \\
(\mathrm{N})\end{array}$ \\
\hline Head/eyes & $36.7 \%(11)$ & $46.7 \%(14)$ & $16.6 \%(5)$ & $16.7 \%(5)$ & $80.0 \%(24)$ & $3.3 \%(1)$ \\
\hline Neck/upper back & $50.0 \%(15)$ & $30.0 \%(9)$ & $20.0 \%(6)$ & $6.7 \%(2)$ & $73.3 \%(22)$ & $20.0 \%(6)$ \\
\hline Low back & $56.7 \%(17)$ & $26.7 \%(8)$ & $16.6 \%(5)$ & $10.0 \%(3)$ & $60.0 \%(18)$ & $30.0 \%(9)$ \\
\hline Shoulder & $63.4 \%(19)$ & $23.3 \%(7)$ & $13.3 \%(4)$ & $16.7 \%(5)$ & $73.3 \%(22)$ & $10.0 \%(3)$ \\
\hline Elbow/ forearm & $43.3 \%(13)$ & $33.3 \%(10)$ & $23.3 \%(7)$ & $6.7 \%(2)$ & $76.7 \%(23)$ & $16.6 \%(5)$ \\
\hline Hand/wrist & $60.0 \%(18)$ & $26.7 \%(8)$ & $13.3 \%(4)$ & $13.3 \%(4)$ & $83.4 \%(25)$ & $3.3 \%(1)$ \\
\hline
\end{tabular}

Changes in the presence of MSD symptoms is shown in Figure 3. The presence of musculoskeletal disorder symptoms were asked in both questionnaires by providing body parts drawing. The respondents will then need to circle the related problem areas for the last 12 months, problem areas that need health care utilization for the 12 months, and problem area that prevented respondents from doing normal activities. The reduction of MSD symptoms presence percentages in neck, upper back and lower back showed a significant improvement of more than 25\%. Apart from that, shoulder, elbows, wrists/ hands and hips / thighs showed an encouraging improvement. 


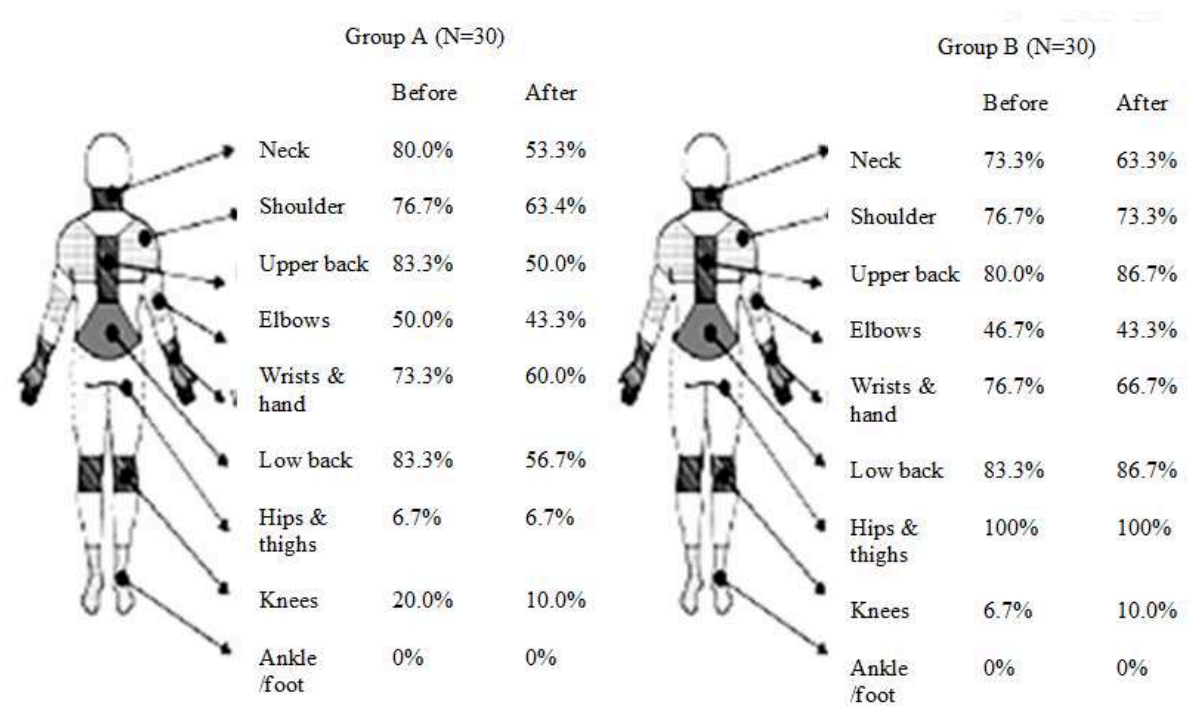

Figure 3. Comparison of MSD symptoms presence percentages before and after ergonomic intervention.

Respondents were also asked to respond to the questions whether workstation ergonomic education and intervention throughout these sixth weeks help them in any ways to improve their workstation work habits. 27 out of 30 respondents (90\%) from Group A agreed with this question, and indicated that the intervention had reduced or eliminated work-related to their back, fingers and shoulders. Changes of working habits after the ergonomic intervention is shown in Table 6 and the new layout after changes is shown in Figure 4.

Table 6 Respondents changes after the six weeks ergonomic interventions.

\begin{tabular}{lcc}
\hline Changes taken after ergonomic intervention & Group A (N=30) & Group B (N=30) \\
Increased awareness of work posture & $90.0 \%(27)$ & $16.7 \%(5)$ \\
\hline Increased awareness of MSD & $86.7 \%(26)$ & $16.7 \%(5)$ \\
Improvement of pains on certain areas & $83.3 \%(25)$ & $6.7 \%(2)$ \\
Adjusted chair height & $83.3 \%(25)$ & $0.0 \%(0)$ \\
Adjusted chair amrest & $83.3 \%(25)$ & $0.0 \%(0)$ \\
Adjusted monitor height & $83.3 \%(25)$ & $0.0 \%(0)$ \\
Adjusted keyboard height & $56.7 \%(17)$ & $0.0 \%(0)$ \\
Adjusted mouse location & $66.7 \%(20)$ & $0.0 \%(0)$ \\
Moved computer to avoid window glare & $86.7 \%(26)$ & $0.0 \%(0)$ \\
Walk around and stretch more frequently & $83.3 \%(25)$ & $0.0 \%(0)$ \\
Started using a footrest & $6.7 \%(2)$ & $0.0 \%(0)$ \\
\hline
\end{tabular}




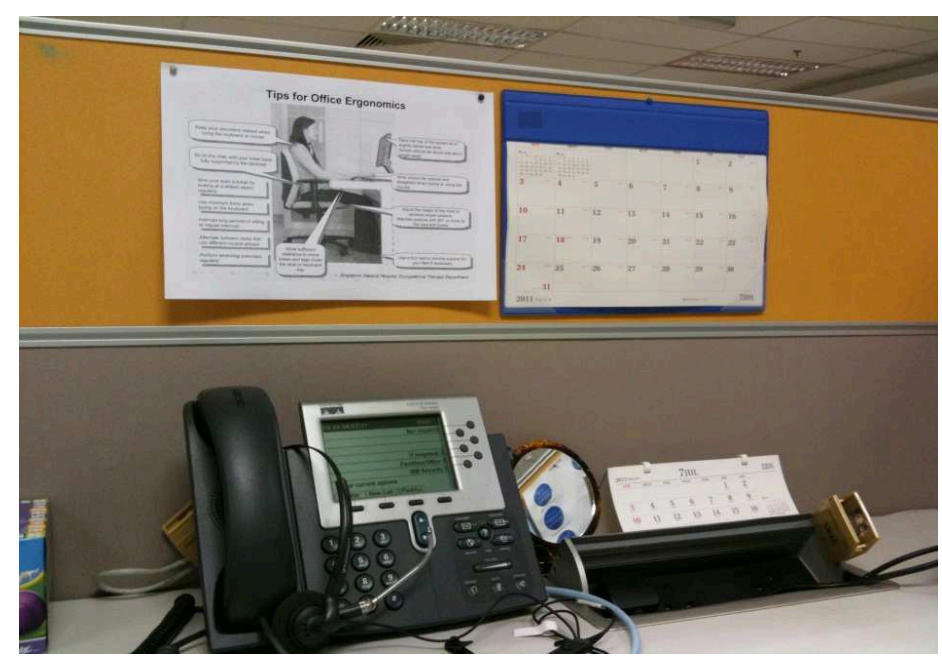

Figure 4 Ergonomic poster on the VDT workstation's wall.

\section{Conclusion}

This case study indicated positive changes in symptom severity and presence of MCD symptoms for the neck/ upper back, the shoulder and the hand/ wrist were observed too. Although the result for the head/ eyes and lower back were not significant, these results are consistent with changes observed in the head and mouse, stress on the neck and upper back are relieved. The same concept applies to mouse positioning, where correct mouse position will relieve stress on the shoulder and the hand/ wrists regions. Thus, workstation ergonomic intervention is effective in reducing musculoskeletal symptoms among VDT workers.

There were also positive changes in work-station configuration and posture, especially user's mouse and head position. Users are aware on the correct office ergomonic working postures, and they will adjust their chair and sitting position accordingly. These also know the importance of stretching their body, as well stand up and walk around for few minutes periodically.

Four changes points were assesed which were changes in workstation configuration, changes in the symptom severity, changes in the presence of MSD symptoms, and improvement of working habits after the ergonomic education. All 4 points indicated a positive results in Group A, compare to control group (Group B). hence, from this cases study, it is noticeable that ergonomic interventions can be associated with changes in both work-related posture and general health of the VDT workers. 


\section{References}

[1] Pillastrini, P., Mugnai, Farneti, C., Bertozzi, L., Bonfiglioli, R., Curti, S., Mattioli, S. \&Violante, F.S Evaluation of Two Preventive Interventions for Reducing Musculoskeletal Complaints in Operators of Video Display Terminals. Physicl Therapy 87(5) (2007) pp.536-544

[2] Deros, B.M., Mohamad, D., Ismail, A.R., Soon, O.W., Lee, K.C. and Nordin, M.S. Recommended chair and work surfaces dimensions of VDT tasks for Malaysian citizens. European Journal of Scientific Research Vol 34 No. 2 (2009) pp. 156-176.

[3] Fogleman, M. \& Lewis, R.J. Factors associated with self-reported musculoskeletal discomfort in video display terminal (VDT) users. International Journal of Industrial Ergonomics 29(6). (2002) pp. 311-318.

[4] Reeves, K.B., Stanfield, J. \& Huges, L. Assesment of video display workstation set up on risk factors associated with the development of low back and neck discomfort. International Journal of Industrial Ergonomics 35. (2005) pp. 593-604.

[5] Haynes, S. Effects of positioning optimization in an alternative computer workstation for people with and witrhout low back pain. International Journal of Industrial Ergonomics 39(5). (2009) pp. 719-727. 